\title{
Latex Metabolome of Euphorbia Species: Geographical and Inter-Species Variation and its Proposed Role in Plant Defense against Herbivores and Pathogens
}

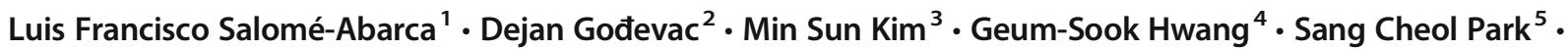 \\ Young Pyo Jang ${ }^{5}$. Cees A. M. J. J. Van Den Hondel ${ }^{6} \cdot$ Robert Verpoorte $^{1}$ • Peter G. L. Klinkhamer ${ }^{7}$. \\ Young Hae Choi $^{1,5}$ (iD
}

Received: 12 December 2020 / Revised: 1 March 2021 / Accepted: 7 April 2021 / Published online: 21 April 2021

(C) The Author(s) 2021

\begin{abstract}
Based on the hypothesis that the variation of the metabolomes of latex is a response to selective pressure and should thus be affected differently from other organs, their variation could provide an insight into the defensive chemical selection of plants. Metabolic profiling was used to compare tissues of three Euphorbia species collected in diverse regions. The metabolic variation of latexes was much more limited than that of other organs. In all the species, the levels of polyisoprenes and terpenes were found to be much higher in latexes than in leaves and roots of the corresponding plants. Polyisoprenes were observed to physically delay the contact of pathogens with plant tissues and their growth. A secondary barrier composed of terpenes in latex and in particular, 24-methylenecycloartanol, exhibited antifungal activity. These results added to the well-known role of enzymes also present in latexes, show that these are part of a cooperative defense system comprising biochemical and physical elements.
\end{abstract}

Keywords Metabolic constriction - Triterpenoids - Chemical defense - Mechanical defense - Chemical selection · 24-methylenecycloartanol

Young Hae Choi

y.choi@chem.leidenuniv.nl

1 Natural Products Laboratory, Institute of Biology, Leiden University, Sylviusweg 72, 2333 BE Leiden, The Netherlands

2 Institute of Chemistry, Technology and Metallurgy, National Institute, University of Belgrade, Studentski trg 12-16, Belgrade 11000, Serbia

3 Food Analysis Center, Korea Food Research Institute, Wanju, Republic of Korea

4 Integrated Metabolomics Research Group, Western Seoul Center, Korea Basic Science Institute, Seoul, Republic of Korea

5 College of Pharmacy, Kyung Hee University, 02447 Seoul, Republic of Korea

6 Department Molecular Microbiology and Biotechnology, Institute of Biology, Leiden University, Sylviusweg 72, 2333 BE Leiden, The Netherlands

7 Plant Ecology and Phytochemistry, Institute of Biology, Leiden University, Sylviusweg 72, 2333 BE Leiden, The Netherlands

\section{Introduction}

Living organisms are constantly challenged by diverse environmental factors, including biotic and abiotic stress (Andrew et al. 2010). In order to survive as a species, they must develop responses during these interactions, evolving genetically and/ or phenotypically (Andrew et al. 2010). Therefore, the biological and chemical complexity of life can be considered to be, to some degree, the consequence of genetic diversity modulated by ecological interactions. Especially in plants, sessility has acted as a strong evolutionary pressure, resulting in the development of diverse physical and biochemical tools as sophisticated adaptive systems. This has allowed them to survive throughout time in diverse ecosystems (Bucharova et al. 2016). Among these tools, plant exudates have attracted great interest due to their adaptive origin, having resulted from their co-evolution with other organisms, including insect herbivores and microorganisms (Konno 2011). Plant exudates represent one of the surface defense layers associated with both primary and secondary strategies such as superficial physical structures (hairs, trichomes, thorns) and specialized metabolites, respectively (Kant et al. 2015). Among plant exudates, latexes have attracted much attention, not only because of 
their commercial value, but also due to their distinctive chemistry, which is assumed to possess ecological potential as a primary barrier in response to exogenous factors (Agrawal and Konno 2009).

Although the specific role of each individual latex metabolite remains unknown, as a whole latex metabolomes are clearly different from those of other organs of the plants exhibiting chemical fingerprints with both quantitative and qualitative differences (Konno et al. 2004; Konno et al. 2006; Seiber et al. 1982). While the role of individual latex metabolites remains largely unknown, as a whole there is undeniable evidence of their involvement in plant defense. For example, the concentration of bioactive metabolites of latex at damaged points before and upon an attack has been shown to be increased (Ball et al. 1997; Gorpenchenko et al. 2019; Hölscher et al. 2016). Latexes have also been recognized as reservoirs of defense-related enzymes (Konno 2011). Several cysteine and serine proteases, protease inhibitors, chitinases, lectins, and oxidases have been isolated and identified from these exudates (Pintus et al. 2010). These enzymes possess numerous physiological roles in signal transduction or oxidative defense systems (Gulsen et al. 2010; Usha-Rani and Jyothsna 2010). Therefore, gaining an insight into the role of latex metabolites and the factors that affect their chemical profiles could contribute to a greater understanding of chemical selection in the evolution of plant defense.

To explore the roles and mechanisms behind latex chemistry and its variations, a method was designed based on the following research questions. Do environmental factors influence the latex metabolome? If so, is this reflected in their role in plant defense system? And what is the outcome of this? Considering the multifactorial nature of the investigated phenomena, a holistic approach was considered to be the most appropriate. The experiments were performed on a set of samples of different genetic (species) and environmental (geographical origin) sources: wild Euphorbia glareosa Pall. Ex M. Bieb., E. amygdaloides L., and E. palustris L. (Euphorbiaceae) specimens collected in different locations in Serbia. The metabolic composition of latexes and tissues from the plants (leaves and roots) were studied by ${ }^{1} \mathrm{H}$ NMR and LC-MS-based metabolomics, and GC-MS and HPTLCDART-MS were used as supplementary tools for a more detailed analysis of targeted metabolites. Based on the results, the anti-herbivory, antibacterial, and antifungal activities of latexes, leaves and roots were tested. This defense might include both chemical and mechanical characters, the former due to a set of specialized metabolites, and the latter by provision of a physical barrier. The independent and complementary roles of these characters have never been explored and thus the effects of chemical extracts and a physical barrier, simulated by a layer of rubber, were tested separately. Subsequently, the degree of chemical and biological variation between samples was correlated in order to determine the roles of some individual metabolites. This holistic approach revealed the effect of environmental factors on the variation of the metabolome of latexes and its correlation with the plants' defense systems.

\section{Methods and Materials}

\section{Plant Material and Collection}

Leaves, roots, and latexes of Euphorbia glareosa Pall. Ex M. Bieb., E. amygdaloides L., and E. palustris L. were collected in several locations in Serbia in June 2017. The samples of E. glareosa were collected at Deliblatska peščara $\left(44^{\circ} 56^{\prime}\right.$

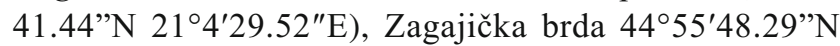
$\left.21^{\circ} 11^{\prime} 51.68^{\prime \prime} \mathrm{E}\right)$, and Titelski breg $\left(45^{\circ} 13^{\prime} 23.92^{\prime \prime} \mathrm{N} 20^{\circ} 13^{\prime}\right.$ $\left.45.03^{\prime \prime} \mathrm{E}\right)$. The samples of $E$. amygdaloides were collected at Avala (444 $\left.41^{\prime} 11.41^{\prime \prime} \mathrm{N} 20^{\circ} 30^{\prime} 53.20^{\prime \prime} \mathrm{E}\right)$, Mali Jastrebac $\left(43^{\circ} 23^{\prime} 3.51^{\prime \prime} \mathrm{N} 21^{\circ} 36^{\prime} 47.97^{\prime \prime} \mathrm{E}\right)$, and Kosmaj (44⒉ $8^{\prime} 28.45^{\prime \prime} \mathrm{N}$ $\left.20^{\circ} 34^{\prime} 28.10^{\prime \prime} \mathrm{E}\right)$. The samples of E. palustris were collected at Borča (44 ${ }^{\circ} 54^{\prime} 48.34$ 'N $\left.20^{\circ} 26^{\prime} 32.51^{\prime \prime} \mathrm{E}\right)$, Čenta $\left(45^{\circ} 5^{\prime} 58.15^{\prime \prime} \mathrm{N}\right.$ $20^{\circ} 22^{\prime} 42.06^{\prime \prime}$ E), and Šajkaš (45 $\left.15^{\circ} 13.14^{\prime \prime} \mathrm{N} 20^{\circ} 6^{\prime} 31.21^{\prime \prime} \mathrm{E}\right)$. The plant material was identified by Pedja Janaćković, and voucher specimens were deposited at the Herbarium of the Botanical Garden "Jevremovac" University of Belgrade, Belgrade, Serbia (voucher numbers: Euphorbia glareosa (BEOU17303), Euphorbia amygdaloides (BEOU17306), and Euphorbia palustris (BEOU17304)).

Latex samples were obtained by making incisions in the plant stems with a sterile razor blade and collecting approximately $1 \mathrm{~mL}$ of latex in a sterile $2 \mathrm{~mL}$-microtube containing $400 \mu \mathrm{L}$ of $\mathrm{MeOH}$. The samples were stored at $-20{ }^{\circ} \mathrm{C}$ until they were freeze-dried. Leaf and root samples were manually collected from the plant and placed into plastic hermetic bags with silica gel and stored in an electric cooling box at $-4{ }^{\circ} \mathrm{C}$ no longer than $8 \mathrm{hr}$. This material was subsequently stored at $-20{ }^{\circ} \mathrm{C}$ until processed (not longer than $24 \mathrm{hr}$ ). The leaf and root samples were processed by grinding with liquid nitrogen and then freeze-drying. Dry leaf $(10 \mathrm{~g})$ and root $(5 \mathrm{~g})$ powders were sonicated with methanol during $15 \mathrm{~min}$. After filtration, the resulting extract was partially dried using a rotary evaporator, and then taken to total dryness with a speed-vacuum drier.

\section{Test Organisms}

Larvae of Mamestra brassicae were kindly provided by Pieter Rouweler from the Entomology Department at Wageningen University. Pseudomonas putida (NCCB26044) was purchased from The Netherlands Culture Collection of Bacteria. Pseudomonas fluorescens and Pseudomonas viridiflava were kindly provided by Dr. Paolina Garbeva (Kurm et al. 2019). Alternaria alternata (CBS 102.47) strain was purchased from 
the collection of the Westerdijk Fungal Biodiversity Institute, and Botrytis cinerea was kindly provided by Dr. Jan van Kan (Van Kan et al. 2017).

\section{Reference Compounds}

$\beta$-Sitosterol, $\alpha$-amyrin, $\beta$-amyrin, oleanolic- and usrosolic acid were purchased from Sigma-Aldrich (St-Louis, MO, USA). 24-Methylencycloartanol was previously isolated from the latex of E. palustris (Krstić et al. 2016).

\section{High Performance Thin Layer Chromatography-Direct Analysis on Real Time-Mass Spectrometry (HPTLC- DART-MS) Analysis}

For thin-layer chromatography (TLC), latex extracts were diluted with methanol to a final concentration of $2 \mathrm{mg} / \mathrm{mL}$. An automatic TLC sampler (ATS 4) (CAMAG, Muttenz, Switzerland) with a $25 \mu \mathrm{L}$ Hamilton syringe was used to apply $30 \mu \mathrm{g}$ of all of the samples as $6 \mathrm{~mm}$ bands on $20 \times 10 \mathrm{~cm}$ HPTLC silica gel plates (60 F254) (Merck). The saturation time was $20 \mathrm{~min}$, and humidity was set to $37 \%$ using a saturated $\mathrm{MgCl}_{2}$ solution. The samples were applied at $20 \mathrm{~mm}$ from the sides and $10 \mathrm{~mm}$ from the bottom of the plate. The distance between bands was $10 \mathrm{~mm}$, resulting in 18 tracks per plate. Chromatographic development was performed in an automatic developer (ADC2) (CAMAG, Muttenz, Switzerland). The samples were separated with a mixture of toluene-ethyl acetate $(8: 2, v / \mathrm{v})$. The solvent migration distance was $75 \mathrm{~mm}$ from the application point. The HPTLC system was controlled by Vision Cats software.

For HPTLC-DART-MS analysis, each track of the plate was cut into $5 \mathrm{~mm}$-wide strips using a smart glass plate cutter (CAMAG, Muttenz, Switzerland). The HPTLC strips were individually transported on a motorized rail to the ionization region. The plates were ionized with a DART ion source (Ion Sense, Tokyo, Japan) using helium gas (purity of 99.999\%) at $450{ }^{\circ} \mathrm{C}$ and $3 \mathrm{~L} \mathrm{~h}^{-1}$. The plate scan speed was $0.2 \mathrm{~mm} \mathrm{~s}^{-1}$, and it was controlled with DART control software (Ion-Sense). The distance from the ion source to the plate was $1.5 \mathrm{~cm}$. Detection was performed with an AccuTOF-TLC (JEOL, Tokyo, Japan) in positive ion mode. The TOF-MS was set with a peak voltage of $800 \mathrm{~V}$ and a detector voltage of $1900 \mathrm{~V}$.

${ }^{1} \mathrm{H}$ NMR analysis.

Freeze-dried latexes $(5 \mathrm{mg})$ were re-suspended in $1 \mathrm{~mL}$ of $\mathrm{CH}_{3} \mathrm{OH}-d_{4}$ containing $0.418 \mathrm{mM}$ hexamethyldisiloxane (HMDSO) as the internal standard, and ultrasonicated for $20 \mathrm{~min}$. For leaf and root samples, $5 \mathrm{mg}$ of the $\mathrm{MeOH}$ extracts were dissolved in $1 \mathrm{~mL}$ of $\mathrm{CH}_{3} \mathrm{OH}-d_{4}$. All solutions were centrifuged at $13,000 \mathrm{rpm}$ for $10 \mathrm{~min}$, and $300 \mu \mathrm{L}$ of the supernatant was transferred into $3 \mathrm{~mm}$-NMR tubes. The ${ }^{1} \mathrm{H}$ NMR analysis was carried out with an AV-600 MHz NMR spectrometer (Bruker, Karlsruhe, Germany), operating at a proton NMR frequency of $600.13 \mathrm{MHz}$. For internal locking, $\mathrm{CH}_{3} \mathrm{OH}-d_{4}$ was used. All ${ }^{1} \mathrm{H}$ NMR consisted of 64 scans requiring $10 \mathrm{~min}$ and $26 \mathrm{sec}$ as acquisition time using the parameters of $0.16 \mathrm{~Hz} /$ point, pulse width $(\mathrm{PW})=30^{\circ}(11.3 \mu \mathrm{s})$, and relaxation time of $1.5 \mathrm{sec}$. A pre-saturation sequence was used to suppress the residual water signal using low power selective irradiation at $\mathrm{H}_{2} \mathrm{O}$ frequency during recycle delay. The FIDs were Fourier transformed with exponential line broadening of $0.3 \mathrm{~Hz}$. The resulting spectra were manually phased, and baseline corrected and calibrated to HMDSO at 0.06 ppm using TOPSPIN V. 3.0 (Bruker).

For quantitation of 24-methylenecycloaratanol, the ratio between its endo $\mathrm{H}-19$ signal $(\delta 0.55)$ and the internal standard (HMDSO) signal $(\delta 0.06)$ was used in the formula: TISTr $\mathrm{x}$ HIST $x$ [IST] / HTS, where TISTr $=$ Ratio between target signal and internal standard signal, HIST $=$ number of protons in the internal standard signal, [IST] $=$ concentration of the internal standard in the sample, HTS = number of protons in the target signal. This formula provided concentration values expressed in $\mu \mathrm{mol} / 5 \mathrm{mg}$ of sample. This data was further transformed into $\mu \mathrm{g} / 5 \mathrm{mg}$ of sample and extrapolated to $\mathrm{mg}$ of 24-methylenecycloartanol per gram of latex.

\section{Gas Chromatography-Mass Spectrometry Analysis}

Dried latexes $(5 \mathrm{mg})$ were extracted with $1 \mathrm{~mL}$ of chloroform. The extract was taken to total dryness with a speed-vacuum dryer. The dried extracts were re-dissolved with $100 \mu \mathrm{L}$ of pyridine by ultrasonication for $5 \mathrm{~min}$. To this, $100 \mu \mathrm{L}$ of BSTFA + TMCS (99:1, Supelco) was added, and the solutions were heated at $80^{\circ} \mathrm{C}$ for $50 \mathrm{~min}$. The solutions were then centrifuged at 13,000 rpm for $10 \mathrm{~min}$, and the supernatants were transferred to micro-inserts for GCMS analysis on a 7890A gas chromatograph equipped with a 7693 automatic sampler coupled to a $5975 \mathrm{C}$ mass singlequadrupole detector (Agilent, Folsom, CA, U.S.A.). Separation was performed on a DB5 GC column $(30 \mathrm{~m} \times 0.25 \mathrm{~mm}, 0.25 \mu \mathrm{m}$ thickness, JW Science, Folsom, CA, U.S.A.) with helium (99.9\% purity) as the carrier gas at a flow rate of $1 \mathrm{~mL} / \mathrm{min}$. The initial oven temperature was $100{ }^{\circ} \mathrm{C}$ for $2 \mathrm{~min}$, and then ramped at $10{ }^{\circ} \mathrm{C} / \mathrm{min}$ to $270{ }^{\circ} \mathrm{C}$, held for $1 \mathrm{~min}$, ramped again to $290{ }^{\circ} \mathrm{C}$ at $5{ }^{\circ} \mathrm{C} / \mathrm{min}$ for $15 \mathrm{~min}$, and then to $300{ }^{\circ} \mathrm{C}$ at $5{ }^{\circ} \mathrm{C} / \mathrm{min}$ and held for $3 \mathrm{~min}$. The injector was set at $280{ }^{\circ} \mathrm{C}$, and $1 \mu \mathrm{L}$ of each sample was injected in splitless mode. The interface temperature was $280^{\circ} \mathrm{C}$, and the ion source and quadrupole temperature of the mass detector was $230{ }^{\circ} \mathrm{C}$ and $150{ }^{\circ} \mathrm{C}$, respectively. Ionization energy in EI mode was $70 \mathrm{eV}$, and peaks were identified by comparison of the ion spectra with those in the NIST library (version 2008). 


\section{Liquid Chromatography-Mass Spectrometry Analysis}

Each latex sample $(5 \mathrm{mg})$ was individually re-suspended in $1 \mathrm{~mL}$ of a methanol-water solution $(80: 20, v / \mathrm{v})$ and ultrasonicated for $15 \mathrm{~min}$. The resulting extracts were diluted in a $1: 10(\mathrm{v} / \mathrm{v})$ ratio to a final concentration of $0.5 \mathrm{mg} \mathrm{mL}^{-1}$. The samples were filtered with $0.20 \mu \mathrm{m}$ regenerated cellulose membrane filters and analyzed using an Acquity UPLC HSS T3 column $(2.1 \mathrm{~mm} \times 100 \mathrm{~mm}, 1.7 \mu \mathrm{m}$; Waters, Milford, MA 01757). Samples were eluted with a gradient of $0.1 \%$ formic acid in water (A) and $0.1 \%$ formic acid in acetonitrile (B) starting at $10 \% \mathrm{~B}(0-30 \mathrm{~min}), 100 \% \mathrm{~B}(30-35 \mathrm{~min})$, and $10 \% \mathrm{~B}(35-40 \mathrm{~min})$ at $40{ }^{\circ} \mathrm{C}$ at a flow rate of $0.3 \mathrm{~mL} \mathrm{~min}^{-1}$.

MS detection was performed on a QTOF mass spectrometer (Bruker Impact HD) equipped with an electrospray ionization (ESI) source. The capillary voltage was $4000 \mathrm{~V}$, and the drying temperature was $350{ }^{\circ} \mathrm{C}$ at $6 \mathrm{~L} \mathrm{~min}^{-1}$. The samples were analyzed in negative and positive mode in the range of 50-1200 Da. Data acquisition, alignment, peak picking, and neutral losses calculations were performed using Progenies QI software version 2.3 (Nonlinear Dynamics: a Waters Company, Newcastle, UK). Quality control (QC) samples consisted of a blend of all samples that was injected every five samples. Extraction solvent was injected as a blank. The data was normalized to total intensity and filtered by deleting mass features detected in blank samples at higher response levels than in latex samples. Data filtering resulted in 8015 mass features for data acquired in positive mode and 2064 features in negative mode.

\section{Metabolite Identification}

Triterpenoid compounds were firstly identified by comparison of their mass spectra with those of the NIST library (version 2008 ) with a match higher than $85 \%$. Moreover, their identification was supported by diagnostic ${ }^{1} \mathrm{H}$ NMR signal assignments in the latex extracts and compared to those reported in literature. Finally, the presence of their molecular ion and corresponding adducts were used when detected in DARTMS to also support identification data. Molecular ion data from LC-MS data was compared to that of Dictionary of Natural Products for compound annotation. A threshold of $10 \mathrm{ppm}$ was set as the mass error for possible matches.

\section{Preparation of Cis-1,4-Polyisoprene (Rubber) Solution}

A sample of rubber ( $5 \mathrm{~g}$; Sigma-Aldrich) was cut into small pieces and placed in $100 \mathrm{~mL}$ of chloroform. The rubber pieces were left in the solvent for $3 \mathrm{hr}$ to swell, and then manually stirred every $20 \mathrm{~min}$ for $1 \mathrm{~min}$ until a semi-clear solution was obtained. The volume was then adjusted to $140 \mathrm{~mL}$ and stirred until a clear rubber slurry was formed.

\section{Anti-Herbivore Assays}

The diet was prepared by mixing $28 \mathrm{~g}$ of agar, $160 \mathrm{~g}$ of cornflower, $50 \mathrm{~g}$ of beer-yeast, $2 \mathrm{~g}$ of sorbic acid, $1.6 \mathrm{~g}$ of methyl4-hydroxybenzoate, $8 \mathrm{~g}$ of ascorbic acid, and $0.1 \mathrm{~g}$ of streptomycin per liter of water. The ingredients were added to warm water with continual stirring. The $\operatorname{diet}(15 \mathrm{~mL})$ was placed in individual plastic containers and left to solidify at room temperature. For treatments, the dry methanol extracts were resuspended in $2 \mathrm{~mL}$ of ultrapure water and ultrasonicated for $10 \mathrm{~min}(2 \mathrm{X})$. These were added to the diets while semiliquid, manually mixed, and left to solidify at room temperature. The treatments consisted of methanol extracts of latexes, leaves, and roots. From the 10 samples from each location of each species, three random samples were mixed to form one composite sample. Therefore, three composite samples from each region of each plant species were obtained for the three tissues, resulting in nine replicates for each species of each tissue and three replicates for different locations. The final concentration of all of the treatments was $200 \mu \mathrm{g} / \mathrm{mL}$. The negative control consisted of ultrapure water, and the positive control was a $200 \mu \mathrm{g} / \mathrm{mL}$ concentration of abamectin in the diet. The weight of the larvae was recorded after $5 \mathrm{~d}$, and the weights of treated and untreated larvae (negative control) were compared.

\section{Antibacterial Assays}

Pseudomonas putida, P. fluorescens and P. viridiflava were inoculated on Mueller-Hinton agar (MHA) plates and incubated overnight at $37^{\circ} \mathrm{C}$. From the overnight cultures, a single colony was used to inoculate $10 \mathrm{~mL}$ of Mueller-Hinton broth (MHB) and incubated at $37{ }^{\circ} \mathrm{C}$ with constant stirring (150 rpm). The bacterial suspensions were further adjusted with the addition of MHB to 0.5 of turbidity of the McFarland scale $\left(10^{6} \mathrm{CFU} / \mathrm{mL}\right)$. The agar plates with treatments were prepared by filling $45 \mathrm{~mm}$ Petri dishes with $7 \mathrm{~mL}$ of MHA.

The broth microdilution method was used to determine the minimal inhibitory concentration (MIC) of the tested triterpenes according to the Clinical Laboratory Standards Institute guideline (NCCLS 2003). The compounds were dissolved in DMSO and diluted to reach final concentrations in the well from $512 \mu \mathrm{g} / \mathrm{mL}$ to $16 \mu \mathrm{g} / \mathrm{mL}$, and then taken to a volume of $100 \mu \mathrm{l}$ in each well with MHB. Each well was then inoculated with $50 \mu \mathrm{l}$ of the $0.5 \mathrm{McFarland}$ bacterial suspensions and incubated for $24 \mathrm{hr}$ at $30^{\circ} \mathrm{C}$. The final concentration of DMSO in the well was $5 \%$, which was also used as a negative control. A $100 \mu \mathrm{g} / \mathrm{mL}$ solution of spectinomycin in one well was used as a positive control. The bacterial growth was measured by optical density at $600 \mathrm{~nm}$ in a well microtiter plate reader (SPARK $10 \mathrm{M}$, TECAN). The MIC value was defined as the lowest concentration of a compound that 
completely inhibited the bacterial growth at $24 \mathrm{hr}$. All experiments were performed by triplicate. For $P$. viridiflava, the inoculations were done in nutrient agar 2 plates, and the assays were carried out in nutrient broth 2 at $28^{\circ} \mathrm{C}$.

To investigate the antibacterial effects of a layer of rubber, the agar plates were prepared by filling $45 \mathrm{~mm}$ Petri dishes with $7 \mathrm{~mL}$ of MHA (nutrient agar 2 for $P$. viridiflava). After medium solidification, $3 \mathrm{~mL}$ of rubber solution was poured over the medium and left to dry for $2 \mathrm{hr}$ in a fume hood, resulting in a homogeneous rubber layer of ca. $0.05 \mathrm{~mm}$ of thickness. Finally, the plates were exposed for $10 \mathrm{~min}$ to UV light for sanitation. The negative controls were MHA plates without rubber covering. Four replicates were performed for treatments and controls of Pseudomonas putida, Pseudomonas fluorescens, and Pseudomonas viridiflava. The bacterial growth was evaluated at $24 \mathrm{hr}$ and $48 \mathrm{hr}$. To determine whether bacteria were able to pass through the rubber layer to the agar, the rubber layer from the inoculated treatment plates was removed, and the plates were incubated for $24 \mathrm{hr}$ at $28 \pm 2{ }^{\circ} \mathrm{C}$. Plates were then inspected for the appearance of bacterial colonies at the inoculation points.

\section{Antifungal Assays}

To assess the antifungal effects of a layer of rubber, plates were prepared similarly to those used for antibacterial assays but using potato dextrose agar (PDA). Agar plugs $(7 \mathrm{~mm}$ ) with Alternaria alternata and Botrytis cinerea were placed on top of the rubber layer of the treated plates. The negative controls were PDA plates without a rubber layer, PDA plates just with rubber solution, and PDA plates with a combination of rubber solution and latex powder. For the latter, E. palustris and E. myrsinites were chosen as models due to their very different triterpenoid profiles. Five milligrams of all samples of each species were mixed to obtain a representative sample of each latex. The latex was then dissolved in the rubber solution to reach a concentration of $200 \mu \mathrm{g} / \mathrm{mL}$. The plates were dried in the same way as in previous experiments. To observe if the fungi grew over the rubber layer or penetrated it, the layer was manually removed from the plate. Four replicates were performed for each fungal strain, and their growth and colony diameter were measured at $48 \mathrm{hr}$. The incubation temperature was $26^{\circ} \mathrm{C}$.

To test the antifungal activity of triterpenes contained in latex and some other common triterpernes, the Minimum Inhibitory approach was used. 24-Methylenecycloartenol and $\beta$-sitosterol, representative of different steps of the phytosterol pathway, and $\alpha$-amyrin, $\beta$-amyrin, ursolic and oleanolic acids, as representative of different steps in the triterpene pathway, were selected to be tested against Botrytis cinerea. The compounds were dissolved in methanol and tested in two-fold dilution series from $2000 \mu \mathrm{g} / \mathrm{mL}$ until $62.5 \mu \mathrm{g} / \mathrm{mL}$. The spore solution was adjusted to $2.5 \times 10^{5}$ spores $/ \mathrm{mL}$ in the well, and the final concentration of methanol in the well was $5 \%$. The plates were sealed with a parafilm layer and incubated at $26^{\circ} \mathrm{C}$. The positive control consisted of nystatin in the same range of concentrations, and the negative control consisted of media with a final concentration of $5 \%$ of methanol in the well. The minimum inhibitory concentration (MIC) was defined as the minimum concentration in which there was total inhibition of fungal growth visible at $16 \mathrm{hr}$. The minimum effective concentration (MEC) was defined as the minimum concentration needed to see a degree of antifungal effect at $16 \mathrm{~h}$. The plates were examined under a stereoscopic microscope at $16 \mathrm{hr}$ intervals to observe any further effects on fungal growth.

\section{Combination Effect of Rubber and 24- Methylencycloartanol}

To explore interactions between cis-1,4-polyisoprene (rubber) and triterpenes, 24-methylencycloartanol $(20 \mathrm{mg})$, a representative latex triterpene, was added to $1 \mathrm{~mL}$ of slurry solution of rubber in chloroform $(36 \mathrm{mg} / \mathrm{mL})$. Separate tubes containing $20 \mathrm{mg}$ of 24-methylencycloartanol dissolved in $1 \mathrm{~mL}$ of chloroform, and tubes containing only $1 \mathrm{~mL}$ of rubber solution were prepared as controls. All tubes were vortexed for $1 \mathrm{~min}$ and then taken to total dryness with a speed-vacuum dryer. Four replicates were performed for all conditions.

\section{Data Processing and Multivariate Data Analysis}

The NMR spectra were bucketed using AMIX 3.9.12 (Bruker BioSpin GmbH, Rheinstetten, Germany). Bucket data were obtained by spectra integration at $0.04 \mathrm{ppm}$ intervals. Peak intensity of individual peaks was scaled to total intensity and recorded from $\delta 0.20$ to 10.02 . Because of the residual signals of $\mathrm{D}_{2} \mathrm{O}$ and $\mathrm{CH}_{3} \mathrm{OH}-d_{4}$, regions of $\delta 4.75-\delta 4.9$ and $\delta 3.28-$ $\delta 3.34$ were excluded from the analysis, respectively. Multivariate data analysis was performed using SIMCA P (v.15, Umeå, Sweden). Principal component analysis (PCA) and partial least square discriminant analysis (PLS-DA) were conducted for ${ }^{1} \mathrm{H}$ NMR and LC-MS data. For PCA and PLS-DA analyses, the data was scaled using the unit variance (UV) method.

To assess the effect of the environmental factors and plant species on the metabolic variation of the samples, a soft independent model of class analogy (SIMCA) analysis was performed using geographical origin and plant species as PCAclasses separately in each plant species. In this model, local PCA models are separately constructed for each set class (geographic origin or plant species). The distances from each sample to each model are calculated and known as distance to the model (DModX). For species effects, the distances to the model (DModx) values were calculated setting each plant species as a PCA-class in the model, and geographical origin 
in each species to detect environmental effects in the separated models (only latexes, only leaves, and only roots). Data was scaled using the UV method, and the DModx values were transformed to their corresponding logarithm values. The logarithmic averaged DModx values $(N=30) \pm$ standard error of each model was used as a measure of the strength of each factor in the chemical homogeneity of the samples. That is, the higher the DModX value, the higher the metabolic variation among samples.

In order to obtain and compare the total correlation of the effects of the geographical origin of the species on the chemical composition of the samples, PLS-DA modelling using UV scaling was also performed on each individual data set. The averaged $Q^{2}$ from the permutation test (100 permutations) was used as a measure of the strength of the effects of the species and geographical origin on the chemical profile differences among the different plant tissues.

For the antifungal bioassays, the radial growth of the treatments was compared to their corresponding control by a Dunnett test setting the control sample as a control for the comparison of the treatments to the control and setting the rubber treatment as a control for its comparison to the latex supplemented treatments $(\alpha=0.05)$ for Alternaria alternata, and after log transformation of the data for Botrytis cinerea. The anti-herbivory activity data variance, homogeneity, and mean comparison were done with a type 2 ANOVA test, and the mean comparison was performed with a least-square means test $(\alpha=0.05)$ after $\log$ transformation using $\mathrm{R}$ software (V 1.1.456).

\section{Results}

\section{Metabolic Variation in Euphorbia Latexes by Geographical Location}

To compare the metabolic variation of each organ and latex, their ${ }^{1} \mathrm{H}$ NMR spectral data were subjected to multivariate data analysis (MVDA). Firstly, the spectra of the samples from the three locations were analyzed by principal component analysis (PCA). As shown in Supplementary Fig. 1, the metabolome of all the profiled samples was distinctive for each Euphorbia species. This was predictable, as the species is a factor known to have a significant effect on the metabolome (Salomé-Abarca et al. 2018). Interestingly, however, the metabolic variation related to the geographical origin of latex samples showed much less variation than leaf and root samples. This is clearly visible in the PCA plot, that shows that latex samples are less or even not at all separated by their geographical origin while their corresponding leaves and roots samples are grouped accordingly (Supplementary Fig. 1).

However, considering that score distances on PCA can only be evaluated by visual inspection and are thus subjective, further MVDA was performed. A soft independent modelling of class analogy (SIMCA) analysis was constructed for the same sample set. For this model, a PCA is built for each set class, and the distance (DModX) between models is measured to determine their similarity or dissimilarity (Eriksson et al. 2011). In this model, the value of the DModX has a direct relation with the metabolic variation among samples. The values of DModX based on their geographical origin were calculated for latexes, leaves and roots of all species, and the obtained values were logarithmic-transformed and averaged to compare their degree of variation. As shown in Fig. 1, the SIMCA model confirmed that the variation in metabolomes among latexes from different geographical origins was much lower than that of leaves and roots for all of the tested species.

To further confirm this, the $Q^{2}$ value (an indicator of correlation) of partial least square-discriminant analysis (PLSDA) was calculated. The $Q^{2}$ value reflects the degree of correlation between the chemical data set and the classes (Eriksson et al. 2011) (geographical origins) and can thus be regarded as a measurement of their degree of total correlation. Consequently, a lower degree of correlation could be anticipated between the latex chemical set and its geographical origins. As shown both by PCA and SIMCA results, geographical factors exert highly differential effects on the metabolic variation of leaves $\left(Q^{2}=0.96 \pm 0.002\right)$ and roots $\left(Q^{2}=0.91 \pm\right.$ $0.012)$, while latexes showed much less correlation $\left(Q^{2}=\right.$ $0.53 \pm 0.220$ ), indicating that they are not affected as much by their geographical origin as their bearing tissues.

All the data analyses confirmed that the metabolome of latexes is more constant than those of leaves and roots. This apparent lack of influence of environmental factors results in a semi-conserved constitutive chemical pool that could act against a broad range of plant enemies. If this were the case, it could also be presumed that latexes are less influenced by the species factor than by geographical locations. Among the tested species, the metabolic variation in latexes (DModX $=$ $0.76 \pm 0.07)$ associated with the species was lower than in roots (DModX $=1.05 \pm 0.08)$ but showed no relevant difference with that of leaves (DModX $=0.76 \pm 0.06)$.

\section{Identification of Discriminating Metabolites}

Comparison of the ${ }^{1} \mathrm{H}$ NMR spectra of leaves, roots, and latexes revealed much higher levels of triterpenes in latexes than in the other tissues. The latex-specific triterpenes were characterized by methyl signals in the $\delta 0.70-\delta 1.90$ range (Supplementary Fig. 2). Additionally, the cyclopropane moiety present in the structure of cycloartanol was identified by two doublets at $\delta 0.55(\mathrm{~d}, J=4.0 \mathrm{~Hz})-\delta 0.35(\mathrm{~d}, J=4.0 \mathrm{~Hz})$ assigned to the 19-endo and 19-exo protons, respectively (Supplementary Fig. 3). The cycloartanols were further confirmed by DART-MS and GC-MS analysis. The direct mass analysis showed $441.4167 \mathrm{~m} / \mathrm{z}$ and $458.4429 \mathrm{~m} / \mathrm{z}$, which 


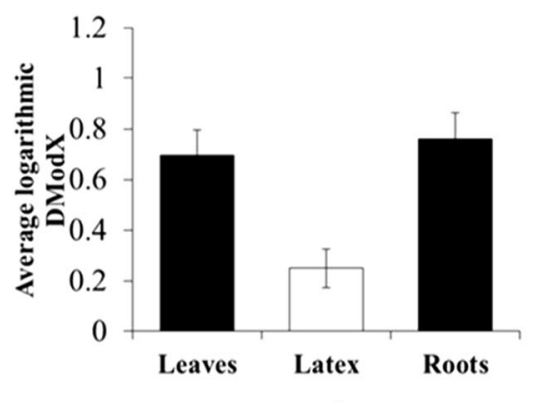

$\mathbf{a}$

Fig. 1 Logarithmic averaged distance to the model (DModX) values in latex, leaves, and roots of three Euphorbia species a Euphorbia amygdaloides, b Euphorbia glareosa. c Euphorbia palustris. The averaged values represent the mean $(N=30 \pm$ standard error) of the DModX

were assigned to the $[\mathrm{M}+\mathrm{H}]^{+}$and $\left[\mathrm{M}+\mathrm{NH}_{4}\right]^{+}$adducts ( mass error $<7$ ppm), respectively, of 24 methylenecycloartanol. In terms of the relative quantitation performed using integration of the $\mathrm{H}-19$ resonance, it was found that the content of the cycloartanol-type triterpenes in latex was over eight times that of the plant tissues (Supplementary Fig. 3) accounting for almost $16 \%$ of the dry weight of Euphorbia glareaosa latexes, $30 \%$ of Euphorbia amygdaloides latexes, and 20\% of Euphorbia palustris latexes. The GC-MS analysis confirmed this, revealing that a few other cycloartane analogues, such as 24-

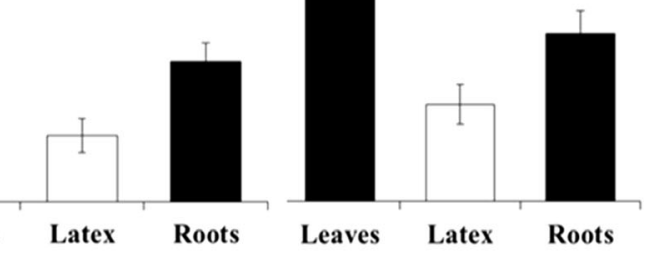

b

from a soft independent model of class analogy (SIMCA) analysis of all samples of leaves, roots, and latex per species. The DModX value is directly related to the metabolic variation among samples

methylenecycloartanone and 24-methylenecycloartanol acetate, were more abundant in latexes than in other organs.

The triterpene 24-methylenecycloartanol was present in all analyzed latexes, but the variation of its content in samples from different geographical locations differed according to the species. For example, while E. glareosa and E. palustrislatex showed no variation, latex from $E$. amygdaloides grown in one of the locations showed a lower concentration while the other two locations showed a similar content (Fig. 2a). However, averaging the samples from all locations, E. amygdaloides had
Fig. 2 Variation of the content of 24-methylenecycloartanol in latexes according to: a geographical variation, and $\mathbf{b}$ species (EG, Euphorbia glareosa, EA, Euphorbia amygdaloides, EP, Euphorbia palustris) $\mathbf{a}$

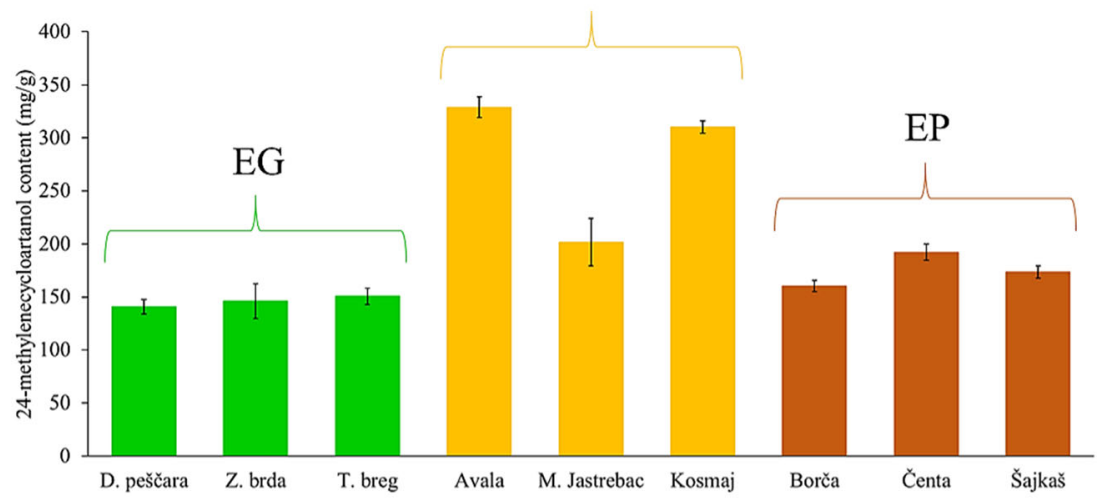

b

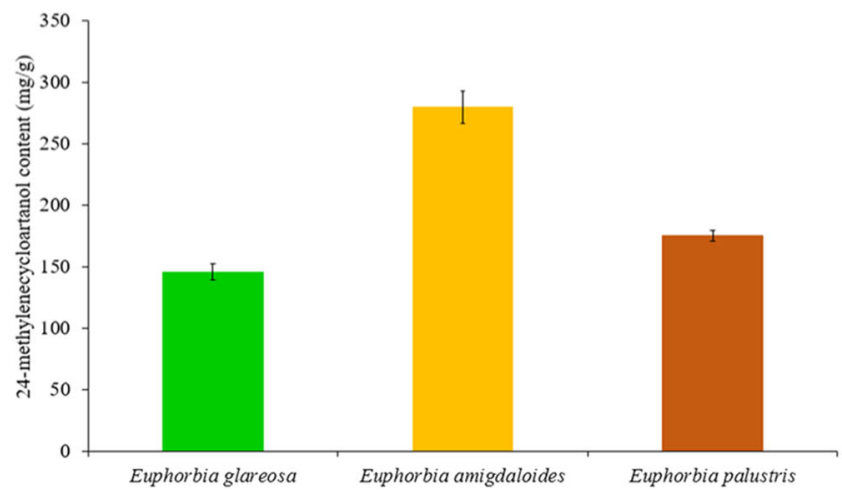


the highest value while the other two species showed similar average content (Fig. 2b). The ${ }^{1} \mathrm{H}$ NMR analysis also revealed the presence of another triterpenoid, cycloeucalenyl acetate, but this metabolite was specific for the latex of E. palustris. This compound was detected as two doublets resonating at $\delta$ $0.41(J=3.95 \mathrm{~Hz}, 1 \mathrm{H})$ and $\delta 0.17(J=4.05 \mathrm{~Hz}, 1 \mathrm{H})$ (Supplementary Fig. 4).

The LC-MS analysis of the latex samples provided further details of their metabolic variation. Similarly to the ${ }^{1} \mathrm{H}$ NMRbased analysis, variation among latex samples from different locations was found to be low, and E. palustris and E. glareosa showed no grouping by geographical origin. However, several species-specific metabolites, such as alkaloids, were detected. Some alkaloids were found to be specific for E. glareosa and E. amygdaloides, while acyl sugars were determined to be more related to E. palustris (Table 1).

\section{Anti-Herbivore Assays}

Latexes, leaf, and root extracts of the three Euphorbia test species were challenged with a generalist herbivore, Mamestra brassicae. The results showed significant antifeeding effects for all three types of extracts of two of the three tested species compared to the negative control $\operatorname{diet}(P<0.05)$ (Fig. 3). In the case of E. palustris, the latex exhibited a lower feeding, but this was not statistically significant $(P>0.05)$, the large standard error being due to one outlier from Borča and one from Čenta, The variation of the anti-herbivore activity (standard error) of the latex was lower than that of leaves and roots in at least two of the three studied species (Fig. 3). This result suggested that the lower chemical variation of latexes was consistent with more homogeneous variation in biological activity against $M$. brassicae.

\section{Antibacterial Assays}

When latex extracts were tested on Pseudomonas viridiflava, $P$. fluorescens and $P$. putida, considered to be general plant pathogens, they did not exhibit any antibacterial activity $(P>0.05)$.

In assays with a layer of rubber over the medium, none of the tested bacteria were able to move through the rubber layer (Supplementary Fig. 5) demonstrating, for the first time, that the mechanical defense of latexes could suffice to defend the plants from bacterial infections, or at least, that the barrier can delay their movement, and thus the onset of an infection.

\section{Antifungal Assays}

A layer of rubber did not indefinitely block the growth of Botrytis cinerea or Alternaria alternata and the fungi were able to penetrate it (Fig. 4a). However, the radial growth of the colony submitted to the rubber treatment was significantly reduced relative to the uncovered control $(P<0.05)$ (Fig. 4a).

When the rubber slurry was supplemented with latex (Fig. $4 \mathrm{~b}$ and $\mathrm{c}$ ), for A. alternata there was a significant decrease
Table 1 Identified discriminant metabolites in Euphorbia palustris, Euphorbia amygdaloides, and Euphorbia glareosa latex collected in different locations of Serbia ( \pm presence/absence of the compound; OM observed mass; ME mass error; IM ionization mode; Ns no cluster separation by PCA; Neg negative ionization mode; Pos positive ionization mode)

\begin{tabular}{|c|c|c|c|c|c|c|c|c|c|c|c|c|}
\hline & & & & \multicolumn{9}{|c|}{ Euphorbia Species } \\
\hline Compound & $\mathrm{OM}$ & ME (ppm) & IM & \multicolumn{3}{|c|}{ E. palustris } & \multicolumn{3}{|c|}{ E. amygdaloides } & \multicolumn{3}{|c|}{ E. glareosa } \\
\hline nicandrose $\mathrm{E}$ & 650.3532 & 2.83 & Neg & \multicolumn{3}{|l|}{+} & \multicolumn{3}{|l|}{-} & \multicolumn{3}{|l|}{-} \\
\hline sibiromycin $^{\mathrm{a}}$ & 648.3371 & 0.08 & Neg & \multicolumn{3}{|l|}{+} & \multicolumn{3}{|l|}{-} & \multicolumn{3}{|l|}{-} \\
\hline asperazine & 664.2791 & -1.06 & Neg & \multicolumn{3}{|l|}{-} & \multicolumn{3}{|l|}{+} & \multicolumn{3}{|l|}{-} \\
\hline milliamine $\mathrm{C}$ & 706.2854 & -5.14 & Neg & \multicolumn{3}{|l|}{-} & \multicolumn{3}{|l|}{+} & \multicolumn{3}{|l|}{-} \\
\hline \multirow[t]{3}{*}{ rankiniridine } & 552.2486 & 2.66 & Neg & - & & & - & & & + & & \\
\hline & & & & \multicolumn{9}{|c|}{ Geographical origin $^{c}$} \\
\hline & & & & Bo & Če & Ša & $\mathrm{Mj}$ & Av & Ko & $\mathrm{Tb}$ & $\mathrm{Dp}$ & $\mathrm{Zb}$ \\
\hline solanoglycosydane I & 576.4099 & -6.80 & Neg & Ns & Ns & Ns & + & - & - & Ns & Ns & Ns \\
\hline plactin & 644.4008 & -0.16 & Neg & Ns & Ns & Ns & + & - & - & Ns & Ns & Ns \\
\hline aphanamolide B & 706.2830 & -0.84 & Neg & Ns & Ns & Ns & - & + & - & Ns & Ns & Ns \\
\hline manadoperoxide $\mathrm{J}$ & 406.7664 & 1.62 & Neg & Ns & Ns & Ns & - & + & - & Ns & Ns & Ns \\
\hline stelleralide C & 666.2976 & -9.55 & Neg & $\mathrm{Ns}$ & Ns & Ns & - & - & + & Ns & Ns & $\mathrm{Ns}$ \\
\hline $\mathrm{C}_{36} \mathrm{H}_{36} \mathrm{~N}_{2} \mathrm{O}_{8}{ }^{\mathrm{b}}$ & 624.2411 & -0.08 & Neg & Ns & Ns & Ns & - & - & + & Ns & Ns & Ns \\
\hline pentaglycerol & 388.1910 & -8.76 & Pos & Ns & Ns & $\mathrm{Ns}$ & + & - & - & Ns & Ns & Ns \\
\hline
\end{tabular}




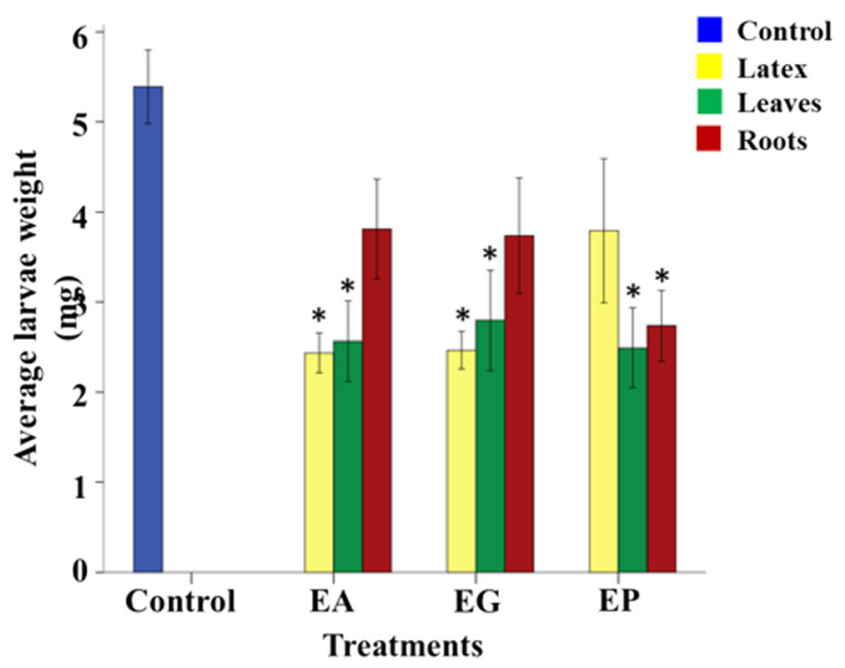

Fig. 3 Anti-herbivore activity from latex, leaves, and roots of Euphorbia amygdaloides, Euphorbia glareosa, and Euphorbia palustris. The values represent the mean value $(N=30) \pm$ standard error. The * represents significant differences between the treatment and the control in a leastsquare means test $(\alpha=0.05)$. EA, Euphorbia amygdaloides, EG, Euphorbia glareosa, EP, Euphorbia palustris
$(P<0.05)$ in radial fungal growth in the latex- supplemented rubber compared to that observed with rubber alone, but not for $B$. cinerea.

The minimum inhibitory concentration (MIC) values of 24methylenecycloartanol and other common steroids and terpenoids, including $\beta$-sitosterol, $\alpha$-amyrin, $\beta$-amyrin, ursolic and oleanolic acids, were determined against $B$. cinerea. With the exception of latex-specific 24-methylenecycloartanol, none of the compounds showed inhibition at the tested concentrations. The MIC value of this triterpene was $2000 \mu \mathrm{g} / \mathrm{mL}$, and the MEC value was in the range $500-1000 \mu \mathrm{g} / \mathrm{mL}$. In contrast, some of the common steroids or triterpenoids displayed a growth-promoting effect on the fungus. For example, ursolic acid exhibited a strong growth-promotion effect in liquid suspensions of fungi $64 \mathrm{hr}$ after inoculation. This indicated that 24-methylenecycloartanol plays a specific role in latex.

\section{Dispersive Effect of Polyisoprene}

The MIC value of 24-methylenecycloartanol is too high to be considered a truly active fungicide. This low activity could be $\mathbf{a}$
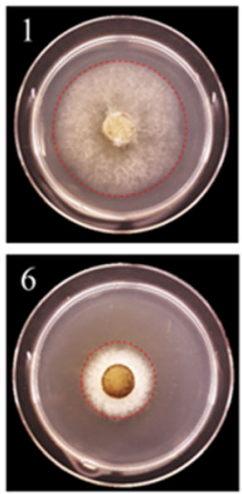

b
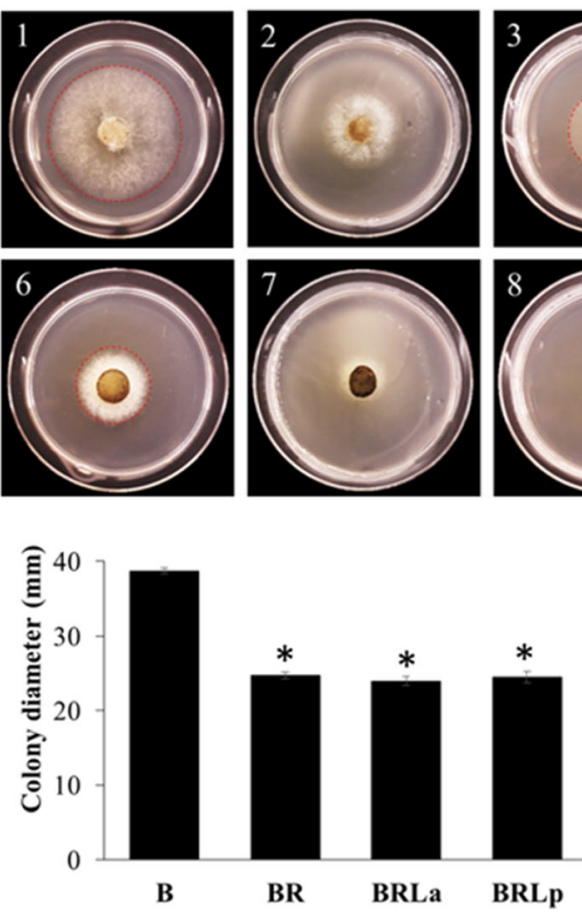
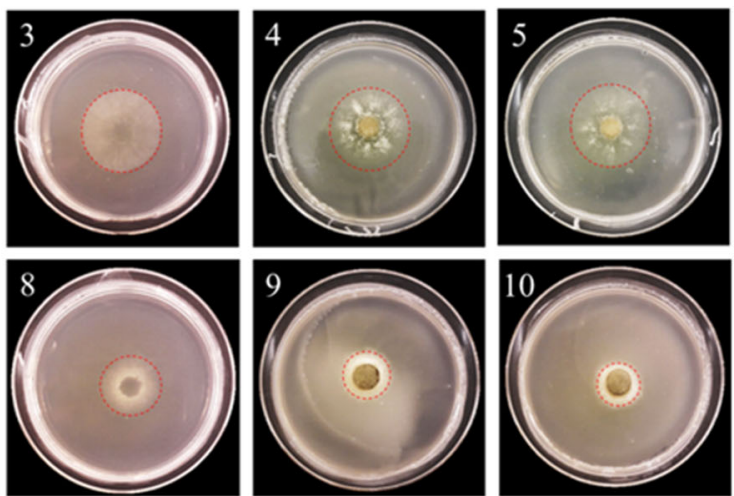

C

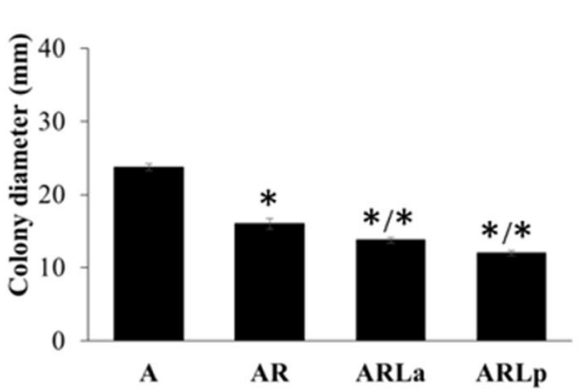

Fig. 4 Antifungal activity of rubber and rubber plus latex against Botrytis cinerea and Alternaria alternata a Radial growth of Botrytis cinerea and Alternaria alternata in control and treated medium at $48 \mathrm{hr}$. 1, Growth control of $B$. cinerea on PDA medium. 2, B. cinerea growing on PDA medium covered with a rubber layer. 3, Mycelium of $B$. cinerea in the agar medium after removing the rubber layer. $4, B$. cinerea growing on PDA medium covered with a rubber layer combined with $200 \mu \mathrm{g} / \mathrm{mL}$ of E. palustris latex. $\mathbf{5}, B$. cinerea growing on PDA medium covered with a rubber layer combined with $200 \mu \mathrm{g} / \mathrm{mL}$ of E. glareosa latex. 6-10 represent the same treatment order, but against Alternaria alternata. b Antifungal activity of rubber and rubber supplemented with latex at $48 \mathrm{hr}$ against $B$. cinerea. The values represent the mean $(N=4) \pm$ standard error. The stars represent significant differences between the treatment and the control $(P \leq 0.05)$ in a Dunnett test; star after a slash indicates significant differences between the treatment the treatment with rubber only $(P \leq 0.05)$ in a Dunnett test. B growth control of Botrytis cinerea; BR covered only with a rubber layer; BRLa, covered with a rubber layer supplemented with latex of E. amygdaloides; BRLp, covered with a rubber layer supplemented with latex of E. palustris. c Antifungal activity of rubber and rubber supplemented with latex at $48 \mathrm{hr}$ against $A$. alternata. The order of treatments is the same as for B. cinera, 
explained partially by its low solubility in the aqueous conditions of the test, and some component/s in the chemical matrix of the latex could act as a solubilizing agent. When a solution of pure 24-methylencycloartanol was dried, the compound crystalized in the bottom of the tube, whereas a mixture with polyisoprene formed a layer coating the wall of the tube and the sterol was determined to be evenly distributed throughout the layer (Supplementary Fig. 6).

\section{Discussion}

The chemical composition of latexes includes three major categories of compounds: polyisoprene polymers (rubber), proteins, and low molecular weight specialized metabolites (Salomé-Abarca et al. 2019). Among these, proteins have been relatively more studied due to their evident biological functions against herbivores and pathogens (Konno 2011; Ramos et al. 2019). In the case of rubber, research has been focused on the coagulation process necessary for industrial purposes, but little is known about its role in defense mechanisms (Wahler et al. 2009). The chemical and biological diversity of latexes lies in the content of specialized metabolites. However, despite their proven biological activities, the potential individual or cooperative roles of these metabolites in the responses of the plants to the environment have not yet been fully explained. To gain a better insight into the nature of the defensive action provided by latex, their susceptibility to changes in environmental conditions was considered to provide essential information.

Due to their superficial anatomical location, latexes are very likely one of the first mechanical and chemical defenses of plants against herbivores and microorganisms (Castelblanque et al. 2016) and precisely because of this, should possess distinctive metabolomes. Furthermore, to be able to fulfil such a role regardless of the plant species, the latex metabolome should be composed of a few selected metabolites, resulting in a semi-conserved constitutive chemical composition that is relatively unaffected by environmental factors. To evaluate this possibility, a systematic approach examining latexes from plants from diverse locations was implemented with the aim of examining the chemical variation of latexes and roles of individual metabolites from plants from the same species but grown in different locations.

The latexes of three latex-bearing species of Euphorbia, collected in nine geographical locations, were metabolically characterized. The degree of metabolic variations of latexes, leaves, and roots of the plants was analyzed using several MVDA methods, including PCA, SIMCA, and PLS-DA. From the analyses, it was found that the metabolome of latexes clearly exhibited considerably lower metabolic variation per location than other parts of the corresponding plants. It is generally accepted that plant metabolomes are largely influenced by environmental factors; and the differences in chemical diversity in ecotypes have been well documented for some species and interpreted as an adaptive response to specific biotic and abiotic factors found in different ecosystems (Salomé-Abarca et al. 2020; Shelton 2004). Moreover, studies on leaf and root samples indicated that each plant species evolves differentiated chemical responses according to its survival requirements both at population and individual levels (Shelton 2004). Contrary to this general rule, the metabolome of latexes was shown to be relatively non- susceptible to changes caused by environmental factors. From a plant defense perspective, this lower metabolic variation of latexes indicates a chemical constitutive role in defense, deployed immediately before a more complex inducible response. Among the selectively accumulated chemical classes in Euphorbia latexes, triterpenes, and in particular, 24methylenecyloartanol, was accumulated in latex rather than in the corresponding plant tissues. Moreover, its concentration was also shown to be quite unaffected by environmental factors and practically constant in all the analyzed Euphorbia species. The same applied for polyisoprenes. Several triterpenoids have been identified in Euphorbia species (Mahlberg and Pleszczynska 1983; Ponsinet and Ourisson 1968) and many of them have been suggested to be chemomarkers for certain taxons (Mahlberg et al. 1987; Mahlberg et al. 1988). Moreover, references show rubber and triterpenes as the main components of rubbery latexes independently of the latex plant-bearing species (Agrawal and Konno 2009; Konno 2011; Ramos et al. 2019; Salomé-Abarca et al. 2019). Also, it has been proposed that given their proximity in biosynthetic pathways, their coexistence in laticifers might have occurred during evolution (Mahlberg 1985; Nemethy et al. 1983; Piazza et al. 1987a, b). This hypothesis, however, does not explain the presence of specific terpenoids in concentrations approximately eight times that of other plant tissues, as observed in our results.

In considering latex as an integral defense system, the role of triterpenes in latexes should be functionally coupled to that of rubber. This would justify their lower degree of variation in latexes, strongly suggesting that their biological activities are mainly related, but not limited, to a constitutive and nontargeted broad protection in an early stage of defense.

To test this hypothesis, the anti-herbivory activities of latexes and the plant tissue extracts were assessed. Latexes, leaves, and roots exhibited almost the same degree of antiherbivory effects against $M$. brassicae, despite possessing largely differentiated metabolomes. However, even with a more limited number of metabolites than those of their bearing plant tissue extracts, latexes exhibited a very effective metabolic composition designed against herbivores. That is, the anti-herbivory activity data of latexes against $M$. brassicae showed a lower variation (standard error) than leaves and roots samples, irrespective of their geographical location. 
Thus, these results suggested that the lower chemical variation of latexes was consistent with more homogeneous variation in biological activity against $M$. brassicae. Consequently, instead of a disadvantage, the low metabolic variation of latexes proved to provide a more stable and consistent protection against herbivores in diverse environmental niches. These results point to a long co-evolution between the plant species and diverse herbivores resulting in the selection of a determined or limited number of compounds to handle a broad range of natural enemies (Firn and Jones 2003). In particular, this conserved metabolome could be more beneficial for a constitutive defense role when dealing with generalist organisms, combining chemical and mechanical features. This is line with the generally accepted concept that when high herbivore pressure conditions are present, as in the case of latexbearing species, the constitutive defenses could create a costbenefit balance in plant fitness (Andrew et al. 2007; Moore et al. 2014). It is important to note that herbivores in these bioassays were exposed to equal dry masses of latex, leaf and root extracts. In natural conditions, it is more likely that herbivores will be exposed to smaller amounts of latex compared to those of leaves or root tissues. While this could imply that the experimental conditions were not entirely realistic, it is important to consider that the amount of exuded latex, depending on the coagulation speed, can vary from some drops to an almost freely flowing stream. Moreover, the quantity of exuded latex can rapidly increase, within minutes, just after herbivory and some insects could even be trapped in the flowing latex. Thus, all in all, the comparison made using the same dry weight comparison is biologically reasonable.

In nature, the most efficient way to deal with a wide range of natural enemies and to avoid the fast development of resistance with a minimal use of resources is to use a cooperative blend of traits (Richards et al. 2010; Richards et al. 2012). If this were the case for latexes, a possible complementary effect between their ingredients is to be expected. To examine this potential cooperative mechanism, the activity of polyisoprene (rubber) was firstly tested against bacteria and fungi. Rubber was found to block the invasion of bacteria completely. In the case of fungi, however, it worked partially, retarding the growth of the pathogenic fungi. This suggested the presence of metabolites that assisted the rubber barrier. Presumably, the hyphae of fungi that survived after penetrating the mechanical rubber barrier then came in direct contact with the latex inside the laticifer, which contains higher concentrations of active metabolites than the coagulated layer. This is where 24methylenecycloartanol, by far the most abundant compound in the analyzed latexes, could act on the fungi. To test this idea, the fungicidal activity of this metabolite against $B$. cinerea was assayed and compared with other common terpenoids and steroids of leaves or roots. Among the tested compounds, only 24-methylenecycloartanol showed antifungal activity against $B$. cinerea. This indicated that $24-$ methylenecycloartanol plays a specific role in latex. Nevertheless, the isolated triterpenoid did not show strong effect on the growth inhibition of $B$. cinerea with relatively high MEC in the range of $500-1000 \mu \mathrm{g} / \mathrm{mL}$. However, the low activity could be overcome by the natural presence in latexes as high as $11,000 \mu \mathrm{g} / \mathrm{mL}$ (Krstić et al. 2016).

These results reveal the existence of a systematic defense mechanism with a complementary effect between rubber and cycloartanol. This is supported by reports of the decrease in the expression of rubber synthesis genes when the expression of triterpene synthesis genes increases (Niephaus et al. 2019; Post et al. 2012). This was all reflected in the metabolome of the latex of E. palustris during fungal infection (Krstić et al. 2016). Thus, the literature and our results demonstrate that the selective accumulation and increase in concentration of 24methylenecycloartanol in Euphorbia latexes is not random. That is, in the point of plant injury-fungal contact, rubber will retard the proliferation of the fungus and the hyphae that penetrate the latex barrier will encounter a high concentration of a specific antifungal component. This highlights how latexes initially deal with a large number of enemies with a very limited number of constitutive compounds.

Another aspect of the complementary mechanism involving cycloartanol and rubber is that rubber could function as a natural dispersive agent for the triterpenoids in latex. The results from the tests performed to demonstrate this, showed that the triterpene-rubber dispersion, rubber films, and their combination with latexes acted as a well-designed cooperative system against bacterial and fungal microorganisms. In this system, the rubber particles function as a carrier and disperser of phytosterols and triterpenes during latex exudation and throughout the whole production of a sealing film after coagulation. Therefore, the complementarity between the mechanical defense (rubber coagulation) and chemical defense (specialized metabolites) resulted in a polymeric film in which embedded metabolites are evenly distributed throughout the whole film to increase its effectiveness over the protected area. In addition to the fungicidal activity and function as a dispersion agent, triterpenes might have other functions. They could contribute to the polymeric structure of polyisoprene to strengthen the defensive barrier, as may be deduced from other related experiments (Mironenko et al. 2016; van Deenen et al. 2019). Further work is needed to understand the specificity of the synergy between latex and cycloartanol in particular, among many other available steroids and triterpenoids.

These findings show the complementation of mechanical and chemical features in a single defense system against herbivores, bacteria, and fungi. In normal conditions the metabolome of latexes presents a semi-conserved constitutive composition, consisting mainly in triterpenes throughout all Euphorbia species, with a very low susceptibility to environmental factors as shown by their low metabolic variation. This lower variation of selected active metabolites also guarantees 
a more constant and stable protection against herbivores. Rubber, one of the ubiquitous metabolites in latexes, showed that its contribution to the defense against bacteria, fungi, and herbivores (Dussourd 1995) is not limited to a physical trapping and blocking capability, but also acts a sort of drug delivery system, especially for terpenoids and probably other lipophilic latex metabolites. The defense system of Euphorbia latexes not only depends on metabolites released during latex exudation, but on their high concentration and potential overexpression in an inducible defense response after latex coagulation. The structural complementation between rubber and some specific metabolites, and the role of inducible metabolites related to rubber synthesis in the latex-borne defense is a promising horizon to explore for new complementary defense mechanisms of latexes.

Supplementary Information The online version contains supplementary material available at https://doi.org/10.1007/s10886-021-01274-x.

Acknowledgements The first author acknowledges the support of the Mexican Scientific Council (CONACyT) for supporting his Ph.D. scholarship (No. 410812).

Author Contributions LFSA contributed to the experimental design, sample collection, bioassays design, interpretation of latex's chemical and ecological aspects, and writing of the manuscript. DG contributed on the sample collection, extraction, and identification of metabolites. MSK and GSH contributed and supervised all the LC-MS analyses and their data analysis. SCP and JPY designed and supervised the HPTLC/ DART-MS analyses. CAMJJVH design and supervised the antimicrobial tests. RV supported the experimental design and the interpretation of latex's chemical aspects. PGLK also supported the interpretation of latex' ecological aspects and anti-herbivore assays. YHC contributed with the experimental design, data analysis, and interpretation of latex's chemical and ecological aspects. All authors revised and corrected the final version of the manuscript.

Funding This research was partially supported by the Korea Basic Science Institute under the R\&D program (Project No. D37700) supervised by the Ministry of Science and ICT.

\section{Declarations}

Conflict of Interest The authors declare no conflict of interests.

Open Access This article is licensed under a Creative Commons Attribution 4.0 International License, which permits use, sharing, adaptation, distribution and reproduction in any medium or format, as long as you give appropriate credit to the original author(s) and the source, provide a link to the Creative Commons licence, and indicate if changes were made. The images or other third party material in this article are included in the article's Creative Commons licence, unless indicated otherwise in a credit line to the material. If material is not included in the article's Creative Commons licence and your intended use is not permitted by statutory regulation or exceeds the permitted use, you will need to obtain permission directly from the copyright holder. To view a copy of this licence, visit http://creativecommons.org/licenses/by/4.0/.

\section{References}

Agrawal AA, Konno K (2009) Latex: a model for understanding mechanisms, ecology, and evolution of plant defense against herbivory. Annu Rev Ecol Evol Syst 40:311-331

Andrew RL, Wallis IR, Harwood CE, Henson M, Foley WJ (2007) Heritable variation in the foliar secondary metabolite sideroxylonal in Eucalyptus confers cross-resistance to herbivores. Oecologia 53: 891-901

Andrew RL, Wallis IR, Harwood CE, Foley WJ (2010) Genetic and environmental contributions to variation and population divergence in a broad-spectrum foliar defense of Eucalyptus tricarpa. Ann Bot 105:707-717

Ball OJP, Barker GM, Prestidge RA, Lauren DR (1997) Distribution and accumulation of the alkaloid peramine in Neotyphodium loliiinfected perennial ryegrass. J Chem Ecol 23:1419-1434

Bucharova A, Frenzel M, Mody K, Parepa M, Durka W, Bossdorf O (2016) Plant ecotype affects interacting organisms across multiple trophic levels. Basic Appl Ecol 17:688-695

Castelblanque L, Balaguer B, Martí C, Rodríguez JJ, Orozco M, Vera P (2016) Novel insights into the organization of laticifer cells: a cell comprising a unified whole system. Plant Physiol 172:1032-1044

Dussourd DE (1995) Entrapment of aphids and whiteflies in lettuce latex. Ann Entomol Soc Am 88(2):163-172

Eriksson L, Byrne T, Johansson E, Trygg J, Vikström C (2011) Process analytical technology (PAT) and quality by design (QbD). In: Eriksson L, Byrne T, Johansson E, Trygg J, Vikström C (eds) Multi- and Megavariate data analysis: basic principles and applications, 3rd edn. Umetrics Academy, Umeå, p 500

Firn RD, Jones CG (2003) Natural products a simple model to explain chemical diversity. Nat Prod Rep 20:382-391

Gorpenchenko TY, Grigorchuk VP, Bulgakov DV, Tchernoded GK, Bulgakov VP (2019) Tempo-spatial pattern of stepharine accumulation in Stephania glabra morphogenic tissues. Int J Mol Sci 20: 808. https://doi.org/10.3390/ijms20040808

Gulsen O, Eickhoff T, Heng-Moss T, Shearman R, Baxendale F, Sarath G, Lee D (2010) Characterization of peroxidase changes in resistant and susceptible warm season turf grasses challenged by Blissus occiduus. Arthropod Plant Interact 4:45-55

Hölscher D, Buerkert A, Schneider B (2016) Phenylphenalenones accumulate in plant tissues of two banana cultivars in response to herbivory by the banana weevil and banana stem weevil. Plants 5:34. https://doi.org/10.3390/plants5030034

Kant MR, Jonckheere W, Knegt B, Lemos F, Liu J, Schimmel BCJ, Villarroel CA, Ataide LMS, Dermauw W, Glas JJ, Egas M, Janssen A, Van Leeuwen T, Schuurink RC, Sabelis MW, Alba JM (2015) Mechanisms and ecological consequences of plant defence induction and suppression in herbivore communities. Ann Bot 115: 1015-1051

Konno K (2011) Plant latex and other exudates as plant defense systems: roles of various defense chemicals and proteins contained therein. Phytochemistry 72:1510-1530

Konno K, Hirayama C, Nakamura M, Tateishi K, Tamura Y, Hatori M, Konno K (2004) Papain protects papaya trees from herbivorous insects: role of cysteine protease in latex. Plant J 37:370-378

Konno K, Ono M, Nakamura M, Tateishi K, Hirayama C, Tamura Y, Hatori M, Konno K (2006) Mulberry latex rich in antidiabetic sugarmimic alkaloids forces dieting on caterpillars. Proc Natl Acad Sci U S A 103:1337-1341

Krstić G, Anđelković B, Choi YH, Vajs V, Stević T, Tešević V, Gođevac D (2016) Metabolic changes in palusrtis latex after fungal infection. Phytochemistry 131:17-25

Kurm V, van der Putten WH, Hol WHG (2019) Cultivation-success of rare soil bacteria is not influenced by incubation time and growth medium. Plos One 14:e210 
Mahlberg P (1985) Triterpenoids in latex: their synthesis and possible role in Euphorbia. Leafy Spurge Symposium, Bozeman, pp 16-18 https://library.ndsu.edu/ir/bitstream/handle/10365/3754/ 1587MA85.PDF? sequence $=1 \&$ is Allowed $=y$. Accessed 26 June 2019

Mahlberg P, Pleszczynska J (1983) Phylogeny of Euphorbia interpreted from sterol composition of latex. In: Felsenstein J (ed) Numerical taxonomy: 50CL504. Springer, Berlin

Mahlberg PG, Pleszczynska J, Furr M (1988) Comparison of latex triterpenoid profiles between normal and cristata taxa of Euphorbia and their chemotaxonomic implications. Monogr Syst Bot 25:623629

Mahlberg PG, Davis DG, Galitz DS, Manners GD (1987) Laticifers and the classification of Euphorbia: the chemotaxonomy of Euphorbia eusla L. Bot J Linn Soc 94:165-180

Mironenko NV, Smuseva SO, Brezhneva TA, Selemenev VF, Nechaeva LS (2016) Computer modeling of triterpene glycosides interaction with natural polymer chitosan. Russ J Gen Chem 86:2526-2533

Moore BD, Andrew RL, Külheim C, Foley WJ (2014) Explaining intraspecific diversity in plant secondary metabolites in an ecological context. New Phytol 201:733-750

NCCLS (2003) Methods for dilution antimicrobial susceptibility tests for bacteria that grow aerobically. In: Document M7-A6. Wayne, NCCLS

Nemethy EK, Skrukrud C, Piazza GJ, Alvin M (1983) Terpenoid biosynthesis in Euphorbia latex. Biochim Biophys Acta 760:343-349

Niephaus E, Muller B, van Deenen N, Lassowskat I, Bonin M, Finkemeier I, Prufer D, Schulze-Gronover C (2019) Uncovering mechanisms of rubber biosynthesis in Taraxacum koksaghyz - role of cis-prenyltransferase-like 1 protein. Plant J 100:591-609

Piazza GJ, Saggese EJ, Spletzer KM (1987a) Triterpene biosynthesis in the latex of Euphorbia lathyris: effect of calmodulin antagonists and chlorinated phenoxy compounds. Plant Physiol 83:177-180

Piazza GJ, Saggese EJ, Spletzer KM (1987b) Triterpene biosynthesis in the latex of Euphorbia lathyris: Calmodulin antagonists are ineffective in whole latex. Plant Physiol 83:181-184

Pintus F, Medda R, Rinaldi AC, Spanò D, Floris G (2010) Euphorbia latex biochemistry: complex interactions in a complex environment. Plant Biosyst 144:381-391

Ponsinet G, Ourisson G (1968) Les triterptnes des latex d'Euphorbia. Contribution à un éttude chimo-systématique du genre Euphorbia. Adansonia 8:227-231

Post J, van Deenen N, Fricke J, Kowalski N, Wurbs D, Schaller H, Eisenreich W, Huber C, Twyman RM, Prüfer D, Schulze-
Gronover C (2012) Laticifer-specific cis-prenyltransferase silencing affects the rubber, triterpene, and inulin content of Taraxacum brevicorniculatum. Plant Physiol 158:1406-1417

Ramos MV, Demarco D, Costa-Souza IC, Diniz Teixeira de Freitas C (2019) Laticifers, latex, and their role in plant defense. Trends Plant Sci 24(6):553-567

Richards LA, Dyer LA, Smilanich AM, Dodson CD (2010) Synergistic effects of amides from two Piper species on generalist and specialist herbivores. J Chem Ecol 36:1105-1113

Richards LA, Dyer LA, Forister ML, Smilanich AM, Dodson CD, Leonard MD, Jeffrey CS (2012) Phytochemical diversity drives plant-insect community diversity. Proc Natl Acad Sci U S A 112: 10973-10978

Salomé-Abarca LF, van der Pas J, Kim HK, van Uffelen GA, Klinkhamer PGL, Choi YH (2018) Metabolic discrimination of pine resins using multiple analytical platforms. Phytochemistry 155:37-44

Salomé-Abarca LF, Klinkhamer PGL, Choi YH (2019) Plant latex, from ecological interests to bioactive chemical resources. Planta Med 85: $856-868$

Salomé-Abarca LF, Mandrone M, Sanna C, Poli F, van der CAMJJ H, PGL K, Choi YH (2020) Metabolic variation in Cistus monspeliensis L. ecotypes correlated to their plant-fungal interactions. Phytochemistry 176:112402

Seiber JN, Nelson CJ, Lee SM (1982) Cardenolides in the latex and leaves of seven Asclepias species and Calotropis procera. Phytochemsitry 21:2343-2348

Shelton AL (2004) Variation in chemical defenses of plants may improve the effectiveness of defense. Evol Ecol Res 6:709-726

Usha-Rani P, Jyothsna Y (2010) Biochemical and enzymatic changes in rice as amechanism of defense. Acta Physiol Plant 32:695-701

van Deenen N, Unland K, Prüfer D, Schulze-Gronover C (2019) Oxidosqualene cyclase knock-down in latex of Taraxacum koksaghyz reduces triterpenes in roots and separated natural rubber. Molecules 24:2703

Van Kan JA, Stassen JH, Mosbach A, Van Der Lee TA, Faino L, Farmer AD, Papasotiriou DG, Zhou S, Seidl MF, Cottam E, Edel D, Hahn M, Schwartz DC, RA Dietrich RA, Widdison S, Scalliet G (2017) A gapless genome sequence of the fungus Botrytis cinerea. Mol Plant Pathol 18:75-89

Wahler D, Schulze-Gronover C, Richter C, Foucu F, Twyman RM, Moerschbacher BM, Fischer R, Muth J, Prüfer D (2009) Polyphenol oxidase silencing affects latex coagulation in Taraxacum species. Plant Physiol 151:334-346 